\title{
PENINGKATAN KINERJA DAN MITIGASI RISIKO RANTAI PASOK AGROINDUSTRI NANAS DI PT GREAT GIANT PINEAPPLE
}

\section{PERFORMANCE IMPROVEMENT AND RISK MITIGATION OF PINEAPPLE AGROINDUSTRY SUPPLY CHAIN AT GREAT GIANT PINEAPPLE CO.}

\author{
Marimin dan Muhammad Iqbal Muzakki \\ Departemen Teknologi Industri Pertanian, Fakultas Teknologi Pertanian, Institut Pertanian Bogor \\ Kampus IPB Darmaga, PO BOX 220 16602, Bogor, Indonesia \\ E-mail: marimin@ipb.ac.id, marimin_07@yahoo.co.id, iqbalmuzakki04@gmail.com
}

Makalah: Diterima 21 Desember 2020; Diperbaiki 6 Juni 2021; Disetujui 25 Juni 2021

\begin{abstract}
Indonesia as one of the biggest pineapple exporters has many competitors in international market. One of the exporters of pineapple product is Great Giant Pineapple Company which has integrated farm and industries. Furthermore, there is a chance for risk to occur in pineapple agroindustry supply chain. According to the case mentioned, a company should make effort to maintaining its supply chain stability. This research aimed to improve the performance and mitigates risks through performance and risk analysis at Great Giant Pineapple Co. The methods used in this research were SCOR-fuzzy-AHP for performance measurement, HOR for risk analysis, and ANP-SWOT for strategy selection. The result for performance measurement in Great Giant Pineapple Co. for its plantation and canned pineapple industry in 2018 were $95.66 \%$ and $91.28 \%$, respectively, while in 2019 were $91.45 \%$ and $94.57 \%$, respectively. Risk analysis identified 22 risk events and 15 risk agents. Nine of the risk agents were prioritized based on ARP score. There were 11 action that were proposed to reduce the risk. Mitigation action that should be done first was enhancing the competencies of workers through training caused of cost effectiveness. Performance improvement was defined by considering the analysis of internal and external factor that the company had. Based on expert's assessments, empowering technology to improve production speed and flexibility is the most influential strategy.
\end{abstract}

Keywords: performance, pineapple agroindustry, risk, supply chain

\section{ABSTRAK}

Indonesia sebagai salah satu eksportir nanas terbesar di dunia memiliki banyak kompetitor di pasar internasional. Salah satu eksportir produk nanas dari Indonesia adalah PT Great Giant Pineapple yang memiliki perkebunan dan industri yang terintegrasi. Selain persaingan, terdapat peluang munculnya risiko pada rantai pasok agroindustri nanas. Berdasarkan hal tersebut, perusahaan perlu melakukan usaha untuk menjaga stabilitas rantai pasoknya. Penelitian ini bertujuan untuk meningkatkan kinerja dan mitigasi risiko rantai pasok melalui analisis kinerja dan risiko pada PT Great Giant Pineapple. Metode yang digunakan adalah SCOR-fuzzy-AHP untuk pengukuran kinerja, HOR untuk analisis risiko, dan ANP-SWOT untuk pemilihan strategi. Hasil pengukuran kinerja perkebunan dan industri pengolahan nanas kaleng PT Great Giant Pineapple pada tahun 2018 masingmasing 95,66\% dan 91,28\%, sedangkan pada tahun 2019 bernilai 91,45\% dan 94,57\%. Analisis risiko mengidentifikasi 22 risk event dan 15 risk agent. Sembilan risk agent ditetapkan sebagai prioritas berdasarkan nilai ARP yang diperoleh. Terdapat 11 aksi yang dapat diterapkan untuk mengatasi risiko tersebut. Aksi mitigasi yang harus didahulukan untuk mengurangi sumber risiko terpilih adalah meningkatkan kompetensi tenaga kerja melalui pelatihan karena efektivitas terhadap biaya. Upaya peningkatan kinerja rantai pasok dirumuskan dengan mempertimbangkan analisis faktor internal dan eksternal. Berdasarkan penilaian para, mengembangkan teknologi untuk meningkatkan kecepatan dan fleksibilitas produksi merupakan strategi peningkatan kinerja rantai pasok yang paling berpengaruh.

Kata kunci: agroindustri nanas, kinerja, rantai pasok, risiko

\section{PENDAHULUAN}

Indonesia merupakan salah satu eksportir nanas terbesar di dunia dengan tujuan ekspor diantaranya Amerika Serikat, Eropa, dan negaranegara Asia. Peluang ekspor nanas sangat besar karena tingginya permintaan untuk produk olahan nanas, salah satunya adalah produk nanas kaleng. Permintaan nanas kaleng pada tahun 2014 mengalami kenaikan permintaan sebesar 29\% dibandingkan dengan permintaan pada tahun 2004. Salah satu faktor yang dapat menyebabkan kenaikan jumlah ekspor nanas kaleng adalah pertumbuhan jumlah penduduk. Kenaikan permintaan tersebut merupakan peluang 
bagi agroindustri nanas, terutama produk nanas kaleng di Indonesia untuk mengembangkan usahanya (Wiranthi dan Mubarok, 2017). Selain itu, nilai ekonomi serta permintaan yang tinggi terhadap nanas menjadikan komoditas ini sebagai salah satu produk unggulan dari sektor hortikultura. Pengembangan agroindustri nanas melalui manajemen rantai pasok menjadi hal yang perlu dipertimbangkan sebagai bentuk pencegahan terhadap masalah yang timbul (Singagerda et al., 2016).

Menurut FAO (2019), Indonesia merupakan negara eksportir nanas kaleng dengan peringkat ketiga setelah Thailand dan Filipina pada tahun 2017. Jika dibandingkan dengan Thailand dan Filipina, volume ekspor nanas kaleng Indonesia masih memiliki selisih yang jauh. Posisi Indonesia yang masih di bawah kompetitornya, yaitu Thailand dan Filipina membuat Indonesia perlu melakukan pengembangan di sektor teknologi dan investasi industri pengolahan untuk meningkatkan kualitas dan kuantitas produk olahan nanas (Wiranthi dan Mubarok, 2017).

Persaingan dalam mempertahankan keberlangsungan rantai pasok menjadi alasan perlunya dilakukan pengukuran kinerja rantai pasok nanas untuk mengetahui tingkat kinerja perusahaan. Pengukuran kinerja rantai pasok menjadi hal penting untuk mengetahui kondisi terkini terkait kemampuan rantai pasok agroindustri nanas. Menurut Marimin dan Safriyana (2018), keberlanjutan suatu proses bisnis rantai pasok dapat dilihat dari tingkat kinerjanya. Hal ini membuat peningkatan kinerja rantai pasok menjadi penting sebagai optimalisasi di masa yang akan dating (Asrol et al., 2017).

Selain kinerja kemampuan rantai pasok agroindustri nanas, risiko juga dapat mempengaruhi keberlangsungan rantai pasok. Adanya risiko yang mempengaruhi kinerja dan kualitas risiko menyebabkan pentingnya identifikasi risiko pada rantai pasok agroindustri nanas. Risiko dapat mengganggu keberlangsungan proses bisnis utama (Setyadi dan Kusumawati, 2016). Hal ini membuat stabilitas rantai pasok perlu dijaga dengan sebuah sistem manajemen risiko. Manajemen risiko merupakan kesatuan dari beberapa proses yang terdiri dari identifikasi risiko, penilaian risiko, mitigasi, monitoring, dan evaluasi (Ulfah, 2016). Manajemen risiko untuk mengatasi dampak yang ditimbulkan dari risiko yang muncul diakukan secara terukur dan sistematis sehingga data dan informasi risiko dapat digunakan sebagai acuan untuk perumusan aksi mitigasi risiko (Safriyana et al., 2019).

Penelitian ini bertujuan untuk mengidentifikasi dan menganalisis struktur rantai pasok agorindustri nanas, mengukur kinerja rantai pasok agroindustri nanas, menganalisis risiko yang berpotensi pada rantai pasok agroindustri nanas, serta menganalisis aksi mitigasi risiko dan strategi peningkatan kinerja rantai pasok agroindustri nanas. Penelitian ini dilakukan pada PT Great Giant Pineapple sebagai salah satu agroindustri nanas di Provinsi Lampung. PT. Great Giant Pineapple memiliki perkebunan dan industri pengolahan nanas kaleng yang terintegrasi. Pengukuran kinerja dilakukan dengan model SCOR-fuzzy-AHP. Pengukuran kinerja rantai pasok merupakan langkah yang sangat penting dalam manajemen rantai pasok. Identifikasi risiko dan aksi mitigasi risiko dapat dilakukan dengan menggunakan metode HOR (House of Risk) (Pujawan dan Geraldin, 2009). Metode HOR berfokus pada pencegahan dengan mengurangi sumber risiko. Adanya manajemen risiko dengan metode HOR dapat meningkatkan kualitas operasional perusahaan dengan cara mengatasi risikorisiko yang mungkin timbul melalui aksi mitigasi risiko (Magdalena dan Vannie, 2019).

Adanya risiko dalam keberlangsungan rantai pasok menyebabkan manajemen risik menjadi hal yang penting untuk dilakukan untuk meminimalisasi kerugian di masa depan (Ulfah et al., 2020). Aksi mitigasi risiko disusun melalui HOR 2. Strategi peningkatan kinerja disusun berdasarkan analisis SWOT dengan memperhatikan faktor internal dan eksternal perusahaan sehingga dapat menjadi gambaran tindakan yang dapat dilakukan perusahaan di masa mendatang untuk menjaga keberlangsungan rantai pasok agroindustri nanas. Pemilihan strategi dilakukan dengan pendekatan metode ANP (Analytical Hierarchy Process).

\section{METODE PENELITIAN}

\section{Kerangka Pemikiran}

Penelitian diawali dengan analisis situasional rantai pasok agroindustri nanas. Analisis kondisi rantai pasok agroindustri nanas dilakukan dengan analisis deskriptif FSCN yang dikembangkan oleh Vorst (2006). Setelah itu dilakukan pengukuran kinerja rantai pasok. Perancangan metrik pengukuran kinerja disusun berdasarkan model SCOR 12.0 oleh APICS (2017).

Pembobotan metrik kinerja dilakukan dengan menggunakan metode Fuzzy-AHP. Nilai persentase aktual merupakan persentase akurasi, kesesuaian, atau nilai perbandingan antara aktual terhadap target perusahaan. Analisis dan mitigasi risiko rantai pasok agroindustri nanas dilakukan dengan menggunakan framework HOR 1 dan HOR 2. Strategi peningkatan kinerja disusun dengan menggunakan analisis ANPSWOT berdasarkan hasil faktor internal dan eksternal perusahaan. Hasil dari seluruh analisis akan dikumpulkan menjadi implikasi manajerial. Kerangka pemikiran penelitian strategi peningkatan kinerja dan mitigasi risiko rantai pasok agroindustri nanas tersedia pada Gambar 1. 


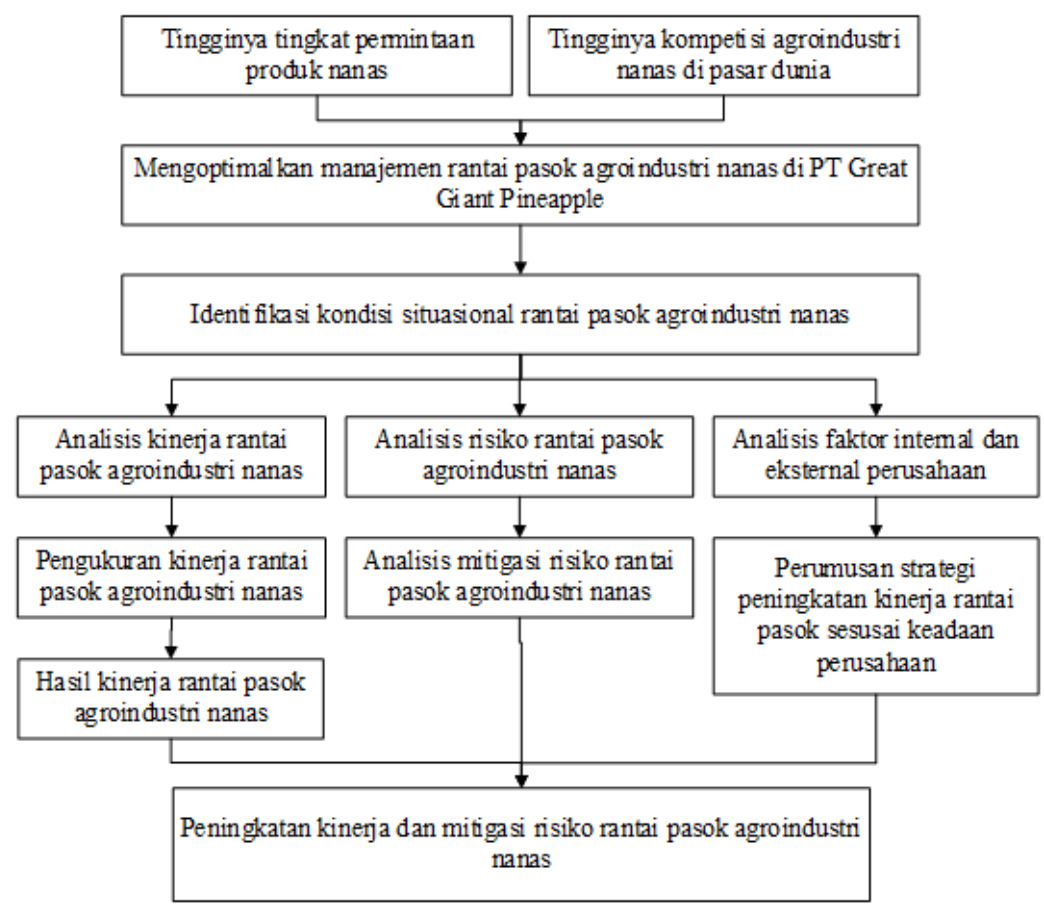

Gambar 1. Kerangka Penelitian

\section{Pengumpulan Data}

Data yang digunakan dalam penelitian terdiri dari data primer dan data sekunder. Data primer diperoleh melalui observasi lapangan, wawancara, dan opini pakar melalui kuisioner. Observasi dilakukan di PT Great Giant Pineapple, Terbanggi Besar Lampung Tengah. Observasi lapangan digunakan untuk analisis situasi rantai pasok, penentuan metrik kinerja, identifikasi risiko, serta faktor internal dan eksternal. Observasi yang dilakukukan meliputi bagian pengolahan buah nanas dimulai dari penerimaan raw material hingga proses labelling.

Wawancara dan opini pakar digunakan untuk mendapatkan pendapat dan penilaian pakar terhadap analisis pengukuran kinerja, analisis risiko, dan analisis peningkatan kinerja. Pakar terdiri dari pakar praktisi dan pakar akademisi. Opini pakar diambil melalui kuisioner yang terdiri dari kuisioner AHP, HOR, dan ANP. Data sekunder didapatkan melalui studi pustaka, dokumentasi perusahaan atau lembaga terkait, serta pusat data seperti FAOSTAT. Data sekunder digunakan untuk menunjang analisis situasional dan pengukuran kinerja rantai pasok.

\section{Analisis Situasional Rantai Pasok Agroindustri Nanas}

Analisis rantai pasok agroindustri nanas dilakukan dengan menggunakan kerangka analisis Vorst (2006). Kerangka tersebut terdiri dari empat elemen yaitu struktur jaringan rantai pasok, manajemen rantai, sumber daya yang digunakan dalam rantai pasok, serta proses bisnis rantai pasok.

\section{Pengukuran Kinerja Rantai Pasok}

Pengukuran kinerja dilakukan dengan menggunakan metode SCOR-fuzzy-AHP. Metode ini diawali dengan penentuan struktur hierarki yang mengacu pada model yang terdapat pada Setiawan et al. (2011) dengan beberapa perubahan dan penyesuaian terhadap SCOR 12.0 dan metrik kinerja yang dapat diukur di lokasi penelitian. Penentuan bobot dilakukan dengan menggunakan pairwise comparisons terhadap pakar, kemudian diolah dengan menggunakan metode fuzzy-AHP. Penelitian menggunakan beberapa orang pakar sehingga perlu dilakukan agregasi. Penggunaan geometric mean untuk menghitung nilai fuzzy gabungan pendapat pakar merupakan metode yang memberikan yang bobot kelompok fuzzy yang paling baik (Meixner, 2009).

Setelah itu dilakukan kalkulasi fuzzy geometric mean dengan menggunakan persamaan 1 (Buckley, 1985; Ahyan, 2013).

$\widetilde{r_{l}}=\left(\prod_{j=1}^{m} \widetilde{a_{l}}\right)^{1 / m}$

Selanjutnya, penentuan bobot fuzzy dilakukan dengan melakukan kalkulasi terhadap fuzzy geometric mean dengan persamaan 2 .

$\widetilde{w_{l}}=\widetilde{r_{l}} \otimes\left(\widetilde{r_{1}} \oplus \widetilde{r_{2}} \oplus \ldots \oplus \widetilde{r_{n}}\right)^{-1}=\left(l w_{i}, m w_{i}, u w_{i}\right)$

Hasil bobot fuzzy akan menghasilkan bobot pada tiap kriteria dengan tiga nilai. Hal ini sesuai dengan konsep triangular fuzzy. Kemudian dilakukan 
proses defuzzifikasi. Proses ini berfungsi untuk mendapatkan nilai tiap kriteria. Defuzzifikasi dapat dilakukan dengan menghitung COA (centre of area) (Tzeng dan Huang, 2011). Kalkulasi COA dapat dilihat pada persamaan 3 .

$\operatorname{COA} w_{i}=\left(\frac{l+m+u}{3}\right)$

Nilai bobot masing-masing elemen kemudian dinormalisasi agar total bobot dari keseluruhan elemen adalah 1. Normalisasi dilakukan dengan membagi bobot tiap elemen dengan jumlah bobot.

Hasil pembobotan metrik kemudian dikombinasikan dengan data persentase aktual perusahaan. Persentase aktual merupakan hasil perbandingan antara data aktual dengan target perusahaan, kesesuaian dengan target, atau persentase akurasi. Perkalian bobot dan persentase aktual tiap metrik akan menghasilkan nilai kinerja perusahaan. Klasifikasi nilai kinerja mengacu pada salah satu skala nilai kinerja yang disusun oleh Marimin et al. (2020) seperti pada Tabel 1.

Tabel 1. Klasifikasi nilai kinerja

\begin{tabular}{cc}
\hline Nilai Kinerja (\%) & Indikator Kerja \\
\hline$<60$ & Buruk \\
$60-64$ & Sangat Kurang \\
$65-69$ & Kurang \\
$70-79$ & Sedang \\
$80-84$ & Baik \\
$85-100$ & Sangat Baik \\
\hline
\end{tabular}

Sumber: Marimin et al. (2020)

\section{Analisis Risiko Rantai Pasok}

Analisis risiko rantai pasok dilakukan dengan metode HOR. Terdapat dua fase metode HOR, yaitu HOR 1 dan HOR 2. Menurut Pujawan dan Geraldin (2009), HOR1 dikembangkan melalui beberapa langkah diantaranya:

1. Melakukan identifikasi terhadap setiap proses bisnis untuk menemukan risk event yang mungkin terjadi pada tiap proses bisnisnya.

2. Memberikan nilai dari dampak (Severity) dari tiap risk event dengan skala 1 sampai 10 dengan nilai 10 merepresentasikan memberikan dampak yang sangat besar yang diadaptasi dari Shahin (2004).

3. Melakukan identifikasi terhadap risk agent dan nilai kemungkinan terjadinya tiap agen risiko dengan skala 1 sampai 10 dengan nilai 10 merepresentasikan selalu terjadi yang diadaptasi dari Shahin (2004).

4. Mengidentifikasi hubungan antara risk event dan risk agent dengan nilai 0,1,3, dan 9

5. Agregat dampak yang dihasilkan oleh risk event dan disebabkan oleh risk agent merupakan nilai yang merepresentasikan identifikasi sebelumnya. Nilai ARPj dapat dihitung dengan menggunakan Persamaan 4.

$$
A R P_{j}=O_{j} \sum_{j} S_{i} R_{i j}
$$

6. Setiap risk agent kemudian diberikan peringkat mulai dari yang tertinggi untuk mengetahui sumber risiko yang potensial untuk diperbaiki.

Menurut Pujawan dan Geraldin (2009), HOR 2 digunakan agar aksi yang terpilih adalah aksi yang tidak sulit untuk dilakukan dan efektif untuk mengurangi risiko yang diprioritaskan oleh perusahaan. Berikut langkah yang harus dilakukan untuk menentukan aksi yang harus dilakukan berdasarkan framework HOR2 (Pujawan dan Geraldin, 2009).

1. Risk agent yang diprioritaskan berdasarkan diagram pareto merupakan input pada HOR 2.

2. Aksi mitigasi risiko disusun berdasarkan risk agent terpilih dan dapat mengatasi beberapa risk agent secara bersamaan.

3. Setiap aksi mitigasi kemudian dianalisis keterkaitannya sebagai bentuk kesesuian aksi terhadap masing-masing risk agent, Ejk dengan nilai $\{0,1,3,9\}$. Nilai 0 merepresentasikan tidak ada hubungan antara aksi $\mathrm{k}$ dan agen $\mathrm{j}$ sedangkan nilai 1,3,9 masing-masing merepresentasikan hubungan yang rendah, sedang, dan tinggi.

4. Total nilai efektik dapat dihitung dengan Persamaan 5.

$T E_{k}=\sum_{j} A R P_{j} E_{j k} \forall k$

5. Setiap aksi perlu dilakukan penilaian terhadap kesulitan penerapannya. Penelitian ini menggunakan skala likert 1-5 dengan nilai 1 merepresentasikan sangat mudah dan nilai 5 merepresentasikan sangat sulit. Derajat kesulitan (Dk) direpresentasikan dengan skala Likert untuk menggambarkan tingkat kesulitan kemampuan biaya dan sumber daya lain yang dibutuhkan untuk menerapkan aksi mitigasi.

6. Nilai total efektivitas terhadap rasio kesulitan $\left(\mathrm{ETD}_{\mathrm{k}}\right)$ dihitung dengan Persamaan 6.

$$
\mathrm{ETD}_{k}=\mathrm{TE}_{k} / \mathrm{D}_{k}
$$

7. Setiap aksi mitigasi ditentukan peringkat berdasarkan nilai $\mathrm{ETD}_{\mathrm{k}}$ dari yang terbesar untuk mengetahui aksi yang diprioritaskan.

\section{Peningkatan Kinerja Rantai Pasok}

Menurut Putri et al. (2013), penggunaan analisis SWOT akan menghasilkan beberapa alternatif yang saling berkaitan dengan memanfaatkan atau mengatasi beberapa faktor SWOT secara bersamaan. Menurut Gabriel (2013), analisis SWOT diawali dengan penilaian masingmasing faktor internal dan eksternal berdasarkan bobot dan rating yang diberikan oleh pakar. Penentuan bobot dilakukan dengan menggunakan pairwise comparisons. Nilai bobot kemudian dihitung dengan Persamaan 7.

$A_{i}=\frac{x_{i}}{\sum_{i=1}^{n} x_{i}}$

Nilai bobot dan rating faktor internal dan eksternal yang didapatkan dari pakar kemudian dilakukan perhitungan bobot rata-rata dan rating rata- 
rata untuk menggabungkan pendapat seluruh penilaian pakar yang terlibat (Alawiyah, 2017). Nilai masing-masing faktor merupakan hasil kali dari bobot rata-rata dan rating rata-rata masing-masing faktor. Total nilai faktor internal dan eksternal akan menggambarkan posisi perusahaan berdasarkan matriks IE. Menurut (Setyorini et al., 2016), matriks IE digunakan untuk melihat posisi kompetitif perusahaan. Matriks IE mengelompokkan posisi perusahaan menjadi tiga kelompok yaitu:

1. Grow and Build (kuadran I, II, dan IV) sehingga perusahaan dapat menerapkan strategi yang bersifat intensif dan integrasi.

2. Hold and Maintain (kuadran III, V, dan VII) dengan tipe strategi umumnya penetrasi pasar, pengembangan produk, dan pengembangan pasar.

3. Harvest and Divest (kuadran VI, VII, dan IX) sehingga perusahaan oerlu menerapkan strategi divestasi.

Pengembangan alternatif strategi dilakukan dengan menggunakan Matriks SWOT. Strategi didapatkan melalui studi pustaka dan diskusi dengan pakar dengan mempertimbangankan faktor SWOT. Matriks SWOT akan menghasilkan alternatifalternatif strategi dengan mempertimbangkan faktor internal dan eksternal yang dimiliki serta posisi perusahaan. Pemilihan strategi dilakukan dengan menggunakan metode ANP berdasarkan model yang dikembangkan oleh Yuksel dan Dagdeviren (2007) dengan memperhatikan ketergantungan antar faktor SWOT. Menurut Shahabi (2014), analisis ketergantungan antara faktor SWOT berdasarkan pendapat yang dominan oleh para pakar. Ketergantungan antara faktor SWOT (W2), akan mempengaruhi bobot global dari masing-masing faktor SWOT. Perubahan bobot pada faktor SWOT juga akan berpengaruh terhadap alternatif strategi yang dipilih oleh pakar. Perhitungan bobot dengan metode ANP dilakukan dengan bantuan software Super decisions (www.superdecisions.com).

\section{HASIL DAN PEMBAHASAN}

\section{Mekanisme Rantai Pasok Agroindustri Nanas}

Anggota rantai pasok agroindustri nanas terdiri dari PT Great Giant Pineapple, konsumen langsung perusahaan, dan konsumen akhir. PT Great Giant Pineapple memiliki perkebunan sebagai penyedia bahan baku dan industri pengolahan yang terintegrasi. Konsumen langsung perusahaan terdiri dari industri lain yang memanfaatkan produk olahan nanas PT Great Giant Pineapple, agen, food service/Horeca, dan industri retail. Produk olahan nanas PT Great Giant Pineapple didominasi oleh nanas kaleng dengan spesifikasi sesuai dengan permintaan konsumen.

Proses bisnis yang terjadi meliputi proses push dan proses pull. Proses push terjadi antara perkebunan dan industri pengolahan, sedangkan proses pull terjadi antara industri pengolahan dan konsumen. Rantai pasok agroindustri nanas memerlukan sumberdaya selama melangsungkan aktivitasnya. Beberapa diantaranya berupa sumber daya fisik atau lahan, sumber daya manusia, serta teknologi pengolahan.

\section{Pembobotan metrik kinerja pengukuran kinerja}

Pembobotan dilakukan terhadap proses bisnis, parameter kinerja, serta atribut dan metrik kinerja yang tersedia pada supply chain operation reference (SCOR). Struktur hierarki pembobotan metrik kinerja didasari oleh model yang dikembangkan oleh Setiawan et al. (2011) dengan beberapa perubahan yang disesuaikan dengan kondisi rantai pasok. Terdapat delapan metrik kinerja yang dipilih untuk mengukur kinerja rantai pasok agroindustri nanas. Pembobotan diperoleh berdasarkan penilaian pakar yag diolah melalui metode fuzzy-AHP. Hasil pembobotan dapat dilihat pada Gambar 2 .

Berdasarkan penilaian, agilitas merupakan atribut kinerja terpenting menurut pakar dengan bobot 0,265. Hal tersebut dikarenakan kemampuan perusahaan dalam merespons perubahan pasar yang diasumsikan oleh target perusahaan juga akan berpengaruh kepada kemampuan perusahaan untuk memenuhi tugasnya, melakukan perubahan kecepatan produksi, serta mengelola biaya dan aset. Metrik kinerja dengan bobot paling tinggi adalah volume produksi saat ini dengan bobot 0,265 yang menggambarkan kemampuan perusahaan dalam merespons perubahan pasar setiap bulannya untuk mempertahankan daya saing perusahaan. Pengukuran kinerja pada tingkat perkebunan tidak dilakukan terhadap seluruh metrik sehingga perlu dilakukan normalisasi bobot terhadap metrik yang digunakan.

\section{Hasil Pengukuran Kinerja Rantai Pasok}

Berdasarkan hasil pengukuran kinerja dengan, PT Great Giant Pineapple memiliki kinerja rantai pasok pada kategori sangat baik berdasarkan klasifikasi oleh Marimin et al. (2020). Hasil pengukuran dapat dilihat pada Tabel 2. Berdasarkan hasil pengukuran, unit perkebunan dan industri pengolahan nanas kaleng PT Great Giant Pineapple pada tahun 2018 berada di kategori sangat baik dengan nilai masing-masing 95,66\% dan 91,28\%. Perusahaan juga memiliki kinerja perkebunan dan industri pengolahan nanas kaleng yang sangat baik pada tahun 2019 dengan nilai masing-masing 91,45\% dan $94,57 \%$. Berdasarkan hasil pengukuran, tidak sesuainya supply bahan baku dapat berdampak pada produktivitas industri pengolahan. Selain itu, banyaknya tenaga kerja dapat menjadi faktor yang berpengaruh terhadap rantai pasok. 


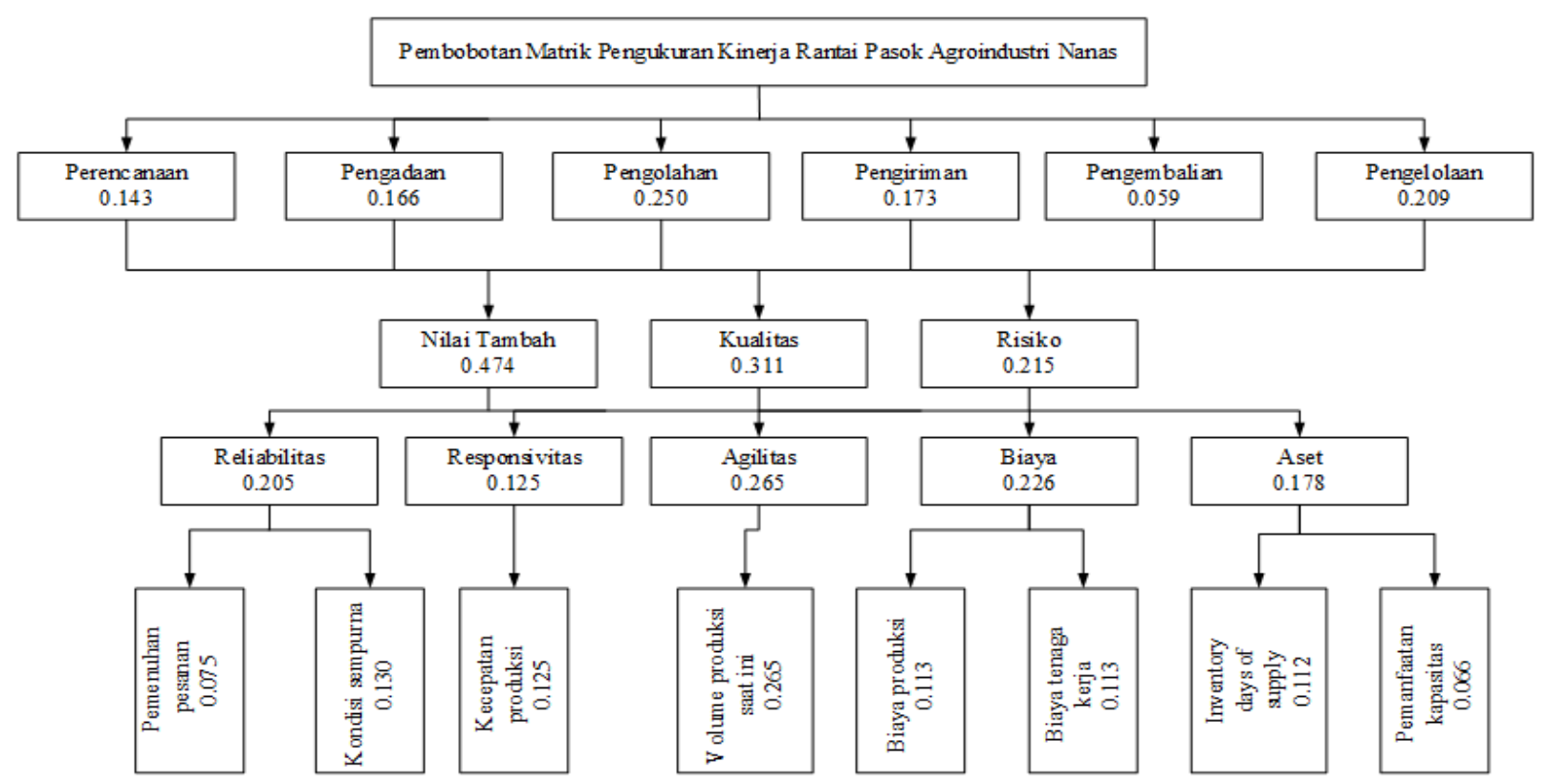

Gambar 2. Struktur dan Bobot AHP

Tabel 2. Nilai kinerja rantai pasok di PT Great Giant Pineapple tahun 2018

\begin{tabular}{llrrrr}
\hline \multirow{2}{*}{ Atribut Kinerja } & \multirow{2}{*}{ Metrik Kinerja } & \multicolumn{2}{c}{ Nilai Tahun 2018(\%) } & \multicolumn{2}{c}{ Nilai Tahun 2019 (\%) } \\
\cline { 2 - 6 } & Kebun & Kebun & Kebun & Pabrik \\
\hline \multirow{2}{*}{ Reliabilitas } & Kondisi Sempurna & 24,83 & 13,01 & 25,43 & 13,01 \\
Responsivitas & Pemenuhan pesanan & 15,64 & 6,91 & 14,58 & 7,34 \\
Agilitas & Kecepatan produksi & - & 12,41 & - & 12,38 \\
Biaya & Volume produksi saat ini & 55,20 & 25,86 & 51,45 & 24,13 \\
& Biaya Produksi & - & 10,89 & - & 10,65 \\
\multirow{2}{*}{ Aset } & Biaya Tenaga kerja & - & 8,24 & - & 9,91 \\
& Pemanfaatan kapasitas & - & 6,58 & - & 6,53 \\
\hline Total & Inventory days of supply & - & 7,38 & - & 10,62 \\
\hline
\end{tabular}

Untuk dapat menentukan strategi yang tepat, perlu dilakukan analisis risiko untuk menekan pengeluaran biaya untuk mengatasi risiko-risiko yang berpeluang muncul.

\section{Hasil Analisis Risiko Rantai Pasok Agroindustri Nanas}

Analisa risk event dilakukan pada proses utama rantai pasok yang terdiri dari perencanaan, pengadaan, pengolahan, pengiriman, dan pengembalian. Terdapat 22 risk event yang teridentifikasi pada ruang lingkup penelitian rantai pasok agroindustri nanas. Risk event teridentifikasi dan nilai severity dapat dilihat pada Tabel 3.

Analisa selanjutnya dilakukan dengan mengidentifikasi risk agent sebagai penyebab terjadinya risk event. Suatu risk agents dapat menyebabkan lebih dari satu risk events sehingga kegiatan pencegahan difokuskan pada risk agents (Tampubolon et al., 2013). Berdasarkan hasil identifikasi, terdapat 15 risk agent. Hasil identifikasi risk agent beserta nilai occurrence dapat dilihat pada Tabel 4.

Metode HOR juga melibatkan analisis risk agent yang diprioritaskan sebagai sumber risiko yang berdampak besar dan harus ditangani. Analisis dilakukan dengan memperhitungkan nilai ARP dari tiap risiko. Terdapat 9 risk agent yang diprioritaskan, yaitu A6, A12, A1, A2, A7, A3, A13, A15, dan A8 yang dapat menyebabkan $83 \%$ dampak keseluruhan. Hasil perhitungan ARP HOR 1 dapat dilihat pada Tabel 5 .

\section{Analisis Aksi Mitigasi Risiko}

Aksi mitigasi risiko disusun berdasarkan risk agent yang diprioritaskan. Terdapat 11 aksi mitigasi yang dapat dilakukan oleh perusahaan untuk mencegah dan meminimalisasi risk agent yang diprioritaskan. Aksi mitigasi kemudian dinilai berdasarkan efektivitasnya terhadap risk agent dan sumber daya yang digunakan untuk implementasinya. Peringkat prioritas aksi mitigasi risiko berdasarkan penilaian pakar dapat dilihat pada Tabel 6 . 
Tabel 3. Hasil identifikasi risk event

\begin{tabular}{llc}
\hline Risk Events & Kode & Severity \\
\hline Ketidaksesuaian perencanaan produksi dengan realisasi & E1 & 6 \\
Ketidaksesuaian ketersediaan bahan baku dengan rancangan & E2 & 4 \\
Perbedaan antara stok fisik dan record sistem & E3 & 3 \\
Ketidaksesuaian proses rantai pasok dengan anggaran biaya & E4 & 7 \\
Keterlambatan kedatangan bahan baku & E5 & 5 \\
Spesifikasi bahan baku tidak sesuai dengan kebutuhan produksi & E6 & 7 \\
Penurunan kualitas bahan baku selama produksi & E7 & 6 \\
Recovery rendah & E8 & 7 \\
Kerusakan produk hasil & E9 & 5 \\
Breakdown mesin produksi & E10 & 8 \\
Keterlambatan proses produksi & E11 & 6 \\
kekurangan jumlah SDM & E13 & 5 \\
Gudang penuh & E13 & 5 \\
Kerusakan produk selama penyimpanan & E14 & 7 \\
Salah label & E15 & 5 \\
Label tidak sempurna & E16 & 5 \\
Breakdown mesin labelling & E17 & 2 \\
Pengiriman produk terlambat & E18 & 6 \\
Kesalahan kuantitas saat pengiriman & E19 & 3 \\
Kesalahan dokumen seal & E20 & 3 \\
Pengembalian produk sisa tidak sesuai lokasi & E21 & 4 \\
\hline
\end{tabular}

Tabel 4. Hasil identifikasi risk agent

\begin{tabular}{llc}
\hline Kode & Risk Agents & Occurrence \\
\hline A1 & Perubahan permintaan dari marketing & 6 \\
A2 & Kesalahan perhitungan perencanaan produksi & 5 \\
A3 & Kerusakan bahan baku selama transportasi & 8 \\
A4 & Keterbatasan jumlah sarana transportasi & 3 \\
A5 & Kondisi sarana pengiriman produk kurang baik & 6 \\
A6 & Kesalahan/kelalaian tenaga kerja & 7 \\
A7 & Kinerja mesin kurang baik & 6 \\
A8 & Kesalahan maintenance & 5 \\
A9 & Gudang bocor & 5 \\
A10 & Penyimpanan produk yang terlalu lama & 5 \\
A11 & Supply energi terganggu & 6 \\
A12 & Kekurangan bahan baku & 6 \\
A13 & Kelebihan bahan baku & 6 \\
A14 & Kesalahan pada sistem informasi & 3 \\
A15 & Overproduction & 3 \\
\hline
\end{tabular}

Tabel 5. Hasil perhitungan ARP HOR 1

\begin{tabular}{lccc}
\hline Risk Agents & Code & ARP & Kumulatif (\%) \\
\hline Kesalahan/kelalaian tenaga kerja & A6 & 2359 & $17 \%$ \\
Kekurangan bahan baku & A12 & 1998 & $32 \%$ \\
Perubahan permintaan dari marketing & A1 & 1470 & $42 \%$ \\
Kesalahan perhitungan perencanaan produksi & A2 & 1345 & $52 \%$ \\
Kinerja mesin kurang baik & A7 & 1296 & $61 \%$ \\
Kerusakan bahan baku selama transportasi & A3 & 832 & $68 \%$ \\
Kelebihan bahan baku & A13 & 792 & $73 \%$ \\
Overproduction & A15 & 729 & $79 \%$ \\
Kesalahan proses maintenance & A8 & 590 & $83 \%$ \\
Supply energi terganggu & A11 & 588 & $87 \%$ \\
Gudang bocor & A9 & 575 & $91 \%$ \\
Penyimpanan produk yang terlalu lama & A10 & 515 & $95 \%$ \\
Kesalahan pada sistem informasi & A14 & 411 & $98 \%$ \\
Kondisi sarana pengiriman produk kurang baik & A5 & 180 & $99 \%$ \\
Keterbatasan jumlah sarana transportasi & A4 & 96 & $100 \%$ \\
\hline
\end{tabular}


Tabel 6. Peringkat prioritas aksi mitigasi risiko

\begin{tabular}{|c|c|c|c|c|}
\hline Kode & Aksi Mitigasi & $\mathbf{D k}$ & ETDk & Peringkat \\
\hline PA1 & Meningkatkan kompetensi tenaga kerja melalui pelatihan & 2 & 13934,00 & 1 \\
\hline PA6 & $\begin{array}{l}\text { Meningkatkan kinerja evaluasi dan koordinasi periodik } \\
\text { terkait bahan baku }\end{array}$ & 2 & 12099,50 & 2 \\
\hline PA9 & $\begin{array}{l}\text { Memperkuat sistem aliran informasi untuk meningkatkan } \\
\text { akurasi informasi secara real-time dengan RFID }\end{array}$ & 4 & 5936,25 & 3 \\
\hline PA5 & $\begin{array}{l}\text { Meningkatkan kinerja maintenance dengan } \\
\text { mengintegrasikan predictive maintenance dengan ERP } \\
\text { secara menyeluruh }\end{array}$ & 3 & 5658,00 & 4 \\
\hline PA2 & Melakukan review dan revisi dokumen work instruction & 2 & 5512,00 & 5 \\
\hline PA7 & $\begin{array}{l}\text { Meningkatkan kerjasama contract growing dengan } \\
\text { petani (sewa lahan) }\end{array}$ & 4 & 4495,50 & 6 \\
\hline PA3 & Mengembangkan otomasi proses produksi & 3 & 4358,67 & 7 \\
\hline PA4 & $\begin{array}{l}\text { Melakukan evaluasi dan perbaikan terkait area kerja, } \\
\text { lingkungan kerja, dan beban kerja }\end{array}$ & 3 & 2359,00 & 8 \\
\hline PA10 & $\begin{array}{l}\text { Optimalisasi penggunaan luas gudang dengan storage } \\
\text { racking system }\end{array}$ & 4 & 2234,25 & 9 \\
\hline PA11 & Penambahan luas area gudang & 5 & 1787,40 & 10 \\
\hline PA8 & Meningkatkan kecepatan fleksibilitas produksi & 3 & 1470,00 & 11 \\
\hline
\end{tabular}

Tabel 7. Faktor Strategis Internal

\begin{tabular}{|c|c|c|c|c|}
\hline No & Faktor Strategis Internal & Bobot & Rating & Nilai \\
\hline & Kekuatan (Strength) & & & \\
\hline 1 & Perkebunan dan unit pengolahan yang terintegrasi & 0,194 & 4,000 & 0,778 \\
\hline 2 & Supply bahan baku tersedia sepanjang tahun & 0,206 & 3,333 & 0,685 \\
\hline 3 & Salah satu produsen olahan nanas terbesar di dunia & 0,200 & 3,333 & 0,667 \\
\hline 4 & $\begin{array}{l}\text { Memiliki berbagai sertifikasi terkait keamanan pangan } \\
\text { Kelemahan (Weakness) }\end{array}$ & 0,189 & 3,667 & 0,693 \\
\hline 1 & $\begin{array}{l}\text { Penggunaan banyak tenaga kerja dapat menimbulkan risiko } \\
\text { human error }\end{array}$ & 0,128 & 2,333 & 0,298 \\
\hline \multirow[t]{3}{*}{2} & $\begin{array}{l}\text { Sistem aliran informasi belum sepenuhnya dilakukan secara } \\
\text { realtime }\end{array}$ & 0,083 & 2,667 & 0,222 \\
\hline & Jumlah Total & $\mathbf{1 , 0 0 0}$ & & \\
\hline & Total Skor Faktor Internal & & & 3,343 \\
\hline
\end{tabular}

Tabel 8. Faktor strategis eksternal

\begin{tabular}{|c|c|c|c|c|}
\hline No & Faktor Strategis Eksternal & Bobot & Rating & Nilai \\
\hline & Peluang (Opportunity) & & & \\
\hline 1 & Tingkat permintaan produk nanas yang cenderung meningkat & 0,192 & 3,667 & 0,703 \\
\hline 2 & Dukungan pemerintah dalam memudahkan kegiatan ekspor & 0,217 & 3,667 & 0,794 \\
\hline 3 & $\begin{array}{l}\text { Ketersediaan teknologi yang dapat diadopsi } \\
\text { Ancaman (Threats) }\end{array}$ & 0,158 & 2,667 & 0,422 \\
\hline 1 & $\begin{array}{l}\text { Perubahan iklim mempengaruhi kualitas dan kuantitas bahan } \\
\text { baku }\end{array}$ & 0,233 & 1,000 & 0,233 \\
\hline \multirow[t]{3}{*}{2} & Produktivitas negara pesaing & 0,200 & 2,333 & 0,467 \\
\hline & Jumlah Total & $\mathbf{1 , 0 0 0}$ & & \\
\hline & Total Skor Faktor Internal & & & 2,619 \\
\hline
\end{tabular}

\section{Pemilihan Strategi Peningkatan Kinerja Rantai Pasok Agroindustri Nanas}

Perumusan strategi peningkatan kinerja rantai pasok didasari oleh analisis SWOT dan penentuan posisi dengan matriks IE. Analisis diawali dengan penilaian faktor internal dan faktor eksternal perusahaan. Hasil analisis faktor internal dan eksternal dapat dilihat pada Tabel 7 dan Tabel 8 . Berdasarkan hasil analisis, perusahaan memiliki faktor internal yang kuat dan faktor eksternal pada tingkat sedang. Perusahaan berada pada sel IV (3,343; 2,619) sesuai dengan Gambar 3. Hal ini menandakan perusahaan dapat menerapkan strategi untuk tumbuh dan berkembang. 


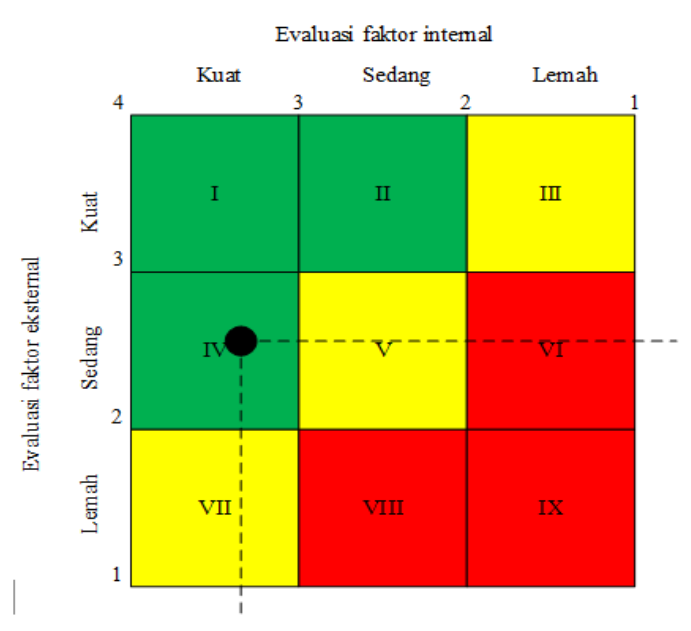

Gambar 3. Posisi perusahaan

Metode AHP-SWOT merupakan metode yang dapat digunakan untuk mendefinisikan hierarki kriteria dan strategi yang diperoleh dari analisis
SWOT. Namun berdasarkan identifikasi dan pendapat pakar, faktor SWOT dapat memiliki hubungan satu sama lain. Hal tersebut dapat mengubah bobot masing-masing faktor dan dapat mempengaruhi pemilihan alternatif strategi. Pemilihan strategi peningkatan kinerja rantai pasok agroindustri nanas dilakukan dengan metode Analytic Network Process (ANP). ANP memiliki kemampuan untuk melakukan penilaian ketergantungan diantara faktor SWOT. Kemampuan tersebut menyebabkan pengambilan keputusan dengan ANP lebih baik daripada metode AHP. Adanya ketergantungan antara komponen SWOT menjadi sebuah keharusan untuk menerapkan metode ANP untuk menentukan faktor, sub-faktor, dan alternatif yang akan dipilih (Shahabi et al., 2014). Struktur ANP yang digunakan dapat dilihat pada Gambar 4. Bobot dari masing-masing alternatif dapat dilihat pada Tabel 9.

Faktor ketergantungan antar faktor SWOT dilakukan dengan menganalisis dampak dari setiap faktor terhadap faktor lainnya menggunakan pairwise comparisons.

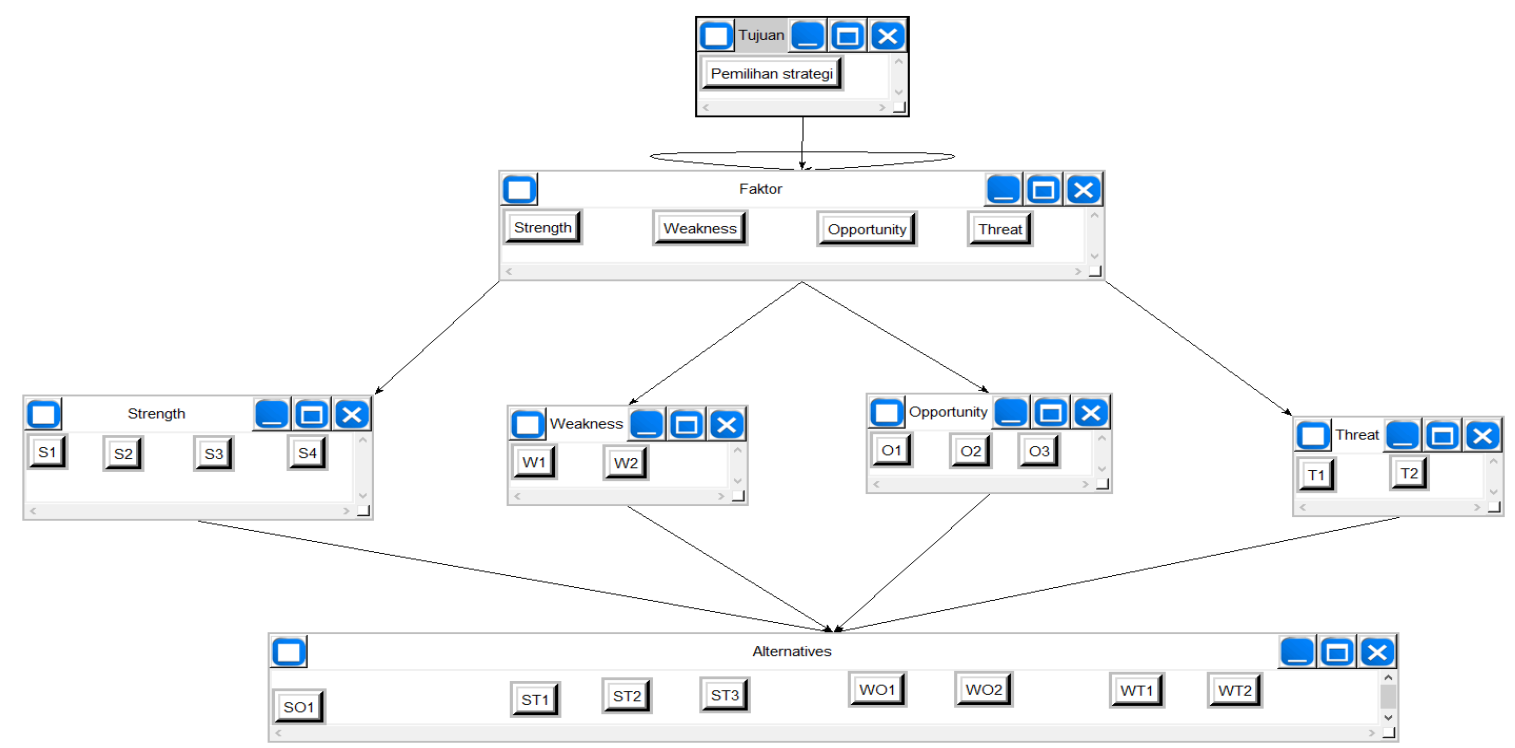

Gambar 4. Struktur ANP analisis SWOT

Tabel 9. Matriks SWOT

\begin{tabular}{|c|c|c|}
\hline Strategi & Kode & Bobot \\
\hline $\begin{array}{l}\text { Mengembangkan teknologi untuk meningkatkan kecepatan produksi dan fleksibilitas } \\
\text { produksi }\end{array}$ & SO1 & 0,410 \\
\hline Memberdayakan sistem otomasi pada proses produksi sebagai pengganti tenaga manusia & WO1 & 0,172 \\
\hline $\begin{array}{l}\text { Meningkatkan investasi dalam penelitian untuk mendapatkan varietas benih yang lebih } \\
\text { tangguh dan produktif }\end{array}$ & WT2 & 0,142 \\
\hline Memaksimalkan kualitas produksi untuk memenangkan persaingan pasar & ST2 & 0,141 \\
\hline Meningkatkan investasi NPD untuk memperoleh segmen pasar baru & ST3 & 0,045 \\
\hline $\begin{array}{l}\text { Memperkuat kerja sama contract growing dengan petani untuk memperoleh alternatif } \\
\text { sumber bahan baku berkelanjutan }\end{array}$ & ST1 & 0,037 \\
\hline $\begin{array}{l}\text { Mengevaluasi dan memperbaiki kualitas lingkungan kerja untuk meningkatkan } \\
\text { produktivitas }\end{array}$ & WT1 & 0,027 \\
\hline Meningkatkan kemampuan sistem ERP untuk mendapatkan basis data realtime & WO2 & 0,026 \\
\hline
\end{tabular}


Input faktor internal dan eksternal didapatkan dari hasi observasi dan wawancara terkait analisis situasional rantai pasok agroindustri nanas, serta didukung dari hasil pengukuran kinerja dan analisis risiko untuk mengetahui kukuatan dan peluang yang dimiliki oleh perusahaan serta kelemahan dan ancaman perusahaan. Berdasarkan prioritas yang didapatkan dengan melibatkan hubungan ketergantungan antar faktor SWOT, terdapat perubahan tingkat kepentingan yang signifikan pada faktor SWOT. Berdasarkan hasil analisis, strategi peningkatan kinerja yang dipilih oleh pakar adalah strategi SO1 dengan bobot 0,410, yaitu mengembangkan teknologi untuk meningkatkan kecepatan dan fleksibilitas produk. Tingginya bobot yang didapatkan tidak dapat terlepas dari kepentingan faktor strength dan opportunity.

Kedua faktor tersebut dinilai sebagai faktor yang menjadi prioritas dalam pengembangan rantai pasok. Opportunity merupakan aspek yang jika dimanfaatkan dengan baik dapat menciptakan kekuatan baru, memitigasi kelemahan, dan ancaman. Strategi ini dilakukan untuk memanfaatkan peluang adanya permintaan nanas yang tinggi, tersedianya teknologi yang dapat diadopsi, dan adanya kemudahan proses ekspor. Selain itu dengan adanya integrasi perkebunan dan pengolahan, strategi ini dapat dilakukan dengan lebih baik karena teknologi yang dapat dikembangkan dapat dimulai dari tingkat perkebunan. Peningkatan kecepatan produksi dapat memaksimalkan kemampuan perusahaan untuk mengambil peluang permintaan produksi yang meningkat serta kemudahan ekspor yang diberikan oleh pemerintah sebesar-besarnya.

\section{Implikasi Manajerial}

Pengukuran kinerja rantai pasok agroindustri nanas dapat dilakukan sebagai langkah untuk memantau tingkat kinerja dan evaluasi kelangsungan rantai pasok. Pengukuran kinerja dilakukan dengan menggunakan dokumentasi bulanan selama satu tahun dan dapat dilakukan secara terintegrasi untuk mengetahui dampak yang ditimbulkan dari masingmasing metrik yang diukur. Berdasarkan hasil penilaian pakar, pengembangan teknologi untuk meningkatkan kecepatan dan fleksibilitas produksi merupakan strategi yang dapat diterapkan untuk memaksimalkan kinerja rantai pasok. Penelitian ini dapat menjadi tambahan informasi untuk pertimbangan perusahaan dalam mengambil keputusan untuk meningkatkan kinerja rantai pasok di masa yang akan datang.

\section{KESIMPULAN DAN SARAN}

\section{Kesimpulan}

Rantai pasok agroindustri nanas melibatkan PT Great Giant Pineapple, konsumen langsung perusahaan, dan konsumen akhir. PT Great Giant Pineapple memiliki unit perkebunan dan pengolahan yang terintegrasi. Secara keseluruhan, PT Great Giant
Pineapple memiliki kinerja perkebunan dan industri pengolahan nanas kaleng yang sangat baik pada tahun 2018 dengan nilai 95,66\% dan 91,28\%. Perusahaan juga memiliki kinerja perkebunan dan industri pengolahan nanas kaleng yang sangat baik pada tahun 2019 dengan nilai masing-masing $91,45 \%$ dan $94,57 \%$. Namun berdasarkan analisis risiko, terdapat sembilan sumber risiko yang perlu diperhatikan oleh perusahaan. Aksi mitigasi meningkatkan kompetensi tenaga kerja melalui pelatihan merupakan aksi yang memiliki efektivitas penggunaan biaya yang besar sehingga aksi ini merupakan aksi yang paling diutamakan menurut penilaian pakar.

Aksi mitigasi tersebut dianggap dapat mengeliminasi beberapa sumber risiko dengan biaya yang tidak terlalu tinggi. Perusahaan memiliki faktor internal yang kuat dan faktor eksternal pada tingkat sedang berdasarkan matriks IE. Faktor internal dan eksternal tersebut disusun berdasrkan hasil observasi terkait kondisi rantai pasok, pengukuran kinerja, serta mempertimbangkan risiko yang diprioritaskan. Penilaian pakar melalui metode ANP-SWOT menunjukkan bahwa mengembangkan teknologi untuk meningkatkan kecepatan dan fleksibilitas produksi merupakan alternatif yang paling berpengaruh menurut pakar untuk meningkatkan kinerja rantai pasok agroindustri nanas dengan bobot 0,410. Perusahaan dapat memaksimalkan aksi mitigasi serta alternatif strategi untuk dapat meminimalisasi risiko serta meningkatkan kinerja rantai pasoknya.

\section{Saran}

Penelitian selanjutnya dapat dilakukan pada ruang lingkup rantai pasok yang lebih luas agar dapat mengevaluasi setiap stakeholder. Risiko jenis lain dapat diidentifikasi agar kondisi rantai pasok tergambar lebih jelas. Selain itu, perlu adanya kajian lebih lanjut terkait untuk mendapatkan alternatif aksi mitigasi risiko dan peningkatan kinerja rantai pasok yang lebih rinci sehingga mudah diterapkan oleh stakeholder.

\section{DAFTAR PUSTAKA}

Alawiyah T. 2017. Pengembangan bisnis tepung mocaf pada CV Agro Nirmala Sejahtera Cianjur-Jawa Barat dengan metode QSPM [Skripsi]. Bogor(ID): Institut Pertanian Bogor.

Ahyan MB. 2013. A fuzzy AHP approach for supplier selection problem: a case study in a gearmotor company. International Journal Managing Value and Supply Chains. 4(3): 11-23. doi: 10.5121/ijmvsc.2013.4302.

APICS. 2017. Supply Chain Operations Reference Model SCOR Version 12.0. Chicago (US): APICS.

Asrol M, Marimin, dan Machfud. 2017. Supply chain performance measurement and improvement for 
sugarcane agro-industry. International Journal Supply Chain Management. 6 (3): 8-21.

Buckley JJ. 1985. Fuzzy hierarchical analysis. Fuzzy Sets and Systems. 17(3): 233-247.

[FAO] Food and Agriculture Organization. 2019. Production of commodity in selected country. [diakses 2020 Jun 19]. Tersedia pada: http://faostat3.fao.org.

Gabriel AA. 2013. Perencanaan strategi pengembangan industry rumah tangga gula kelapa (studi kasus industri rumah tangga gula kelapa Desa Gledug, Kecamatan Sanankulon, Kabupaten Blitar) [Skripsi]. Malang (ID): Universitas Brawijaya.

Magdalena R dan Vannie. 2019. Analisis risiko supply chain dengan model house of risk (HOR) pada PT Tatalogam Lestari. Jurnal Teknik Industri. 14(2): 53-62.

Marimin, Djatna T, Machfud, Asrol M, Papilo P, Taufik B, Darmawan MA. 2020. Supply chain performance measurement and improvement of palm oil agroindustry: a case study at Riau and Jambi Province. IOP Conference Series: Earth and Environmental Science. 443(2020).

Marimin dan Safriyana. 2018. Evaluation of palm oil supply chain's performance, added value, and performance improvement: a case study at x co. IOP Conf. Series: Earth and Environmental Science. 196 (2018): 1-12. doi: 10.1088/17551315/196/1/012001.

Meixner O. 2009. Fuzzy AHP group decision analysis and its application for the evaluation of energy sources. In Proceedings of the 10th International Symposium on the Analytic Hierarchy/Network Process, Pittsburgh, PA, USA (Vol. 29).

Pujawan IN dan Geraldin LH. 2009. House of risk: a model for proactive supply chain risk management. Business Process Management. 15(6): 953-967. doi: $10.1108 / 14637150911003801$.

Putri NE, Astuti R, dan Putri SA. 2014. Perencanaan strategi pengembangan restoran menggunakan analisis SWOT dan metode QSPM (quantitative strategic planning matriks) (studi kasus restoran big burger malang). Jurnal Industria. 3(2): 95106.

Safriyana, Marimin, Anggraeni E, Sailah I. 2019. Operational risk evaluation and mitigation for palm oil supply chain: a case study at x co.. IOP Conf. Series: Earth and Environmental Science. 335 (2019): 1-13. doi: 10.1088/17551315/335/1/012013.

Setiawan A, Marimin, Arkeman Y, Udih F. 2011. Studi peningkatan kinerja manajemen rantai pasok sayuran dataran tinggi di Jawa Barat. Agritech. 31(1): 60-70.
Setyadi G dan Kusumawati Y. 2016. Mitigasi risiko asset dan komponen teknologi informasi berdasarkan kerangka kerja OCTAVE dan FMEA pada Universitas Dian Nuswantoro. Journal Information System. 1(1): 1-10.

Setyorini H, Effendi M, dan Santoso I. 2016. Analisis strategi pemasaran menggunakan matriks SWOT dan QSPM (studi kasus: Restoran WS Soekarno Hatta Malang). Jurnal Teknologi dan Manajemen Agroindustri. 5(1): 46-53.

Shahabi SR, Basiri MH, Kahag MR, Zonouzi SA. 2014. An ANP-SWOT approach for interdependency analysis and prioritizing the Iran's steel scrap industry strategies. Resources Policy. $\quad 42(2014)$ : 18-26. doi: 10.1016/j.resourpol.2014.07.001.

Shahin A. 2004. Integration of FMEA and the kano model. International Journal Quality and Reliability Management. 21(7): 731-746.

Singagerda, Santi F, Marantika, Abshor. 2016. Indonesia pineapple supply chain management and the improvement of global market and competitiveness. ICEBM 2016. (2016).

Tampubolon F, Bahaudin A, dan Ferdinant PF. 2013. Pengelolaan risiko supply chain dengan metode house of risk. Jurnal Teknik Industri. 1(3): 222226.

Tzeng GH dan Huang JJ. 2011. Multiple Attribute Decision Making: Methods and Applications. New York (US): CRC Press.

Ulfah M, Maarif MS, dan Raharja S. 2016. Anaisis dan perbaikan manajemen risiko rantai pasok gula rafinasi dengan pendekatan house of risk. Jurnal Teknologi Industri Pertanian. 26(1): 87103.

Ulfah M. 2016. Rancang bangun model manajemen risiko rantai pasok gula rafinasi [Disertasi]. Bogor (ID): Institut Pertanian Bogor.

Vorst JVD. 2006. Performance Measurement in Agrifood Supply Chain Networks: an overview. Dalam: Quantifying the Agri-food Supply Chain 13-24.

Wiranthi PE dan Mubarok F. 2017. Competitiveness and the factors affecting export of the Indonesia canned pineapple in the world and the destination countries. $2^{\text {nd }}$ International Conference on Sustainable Agriculture and Food Security: A Comprehensive Apporach. KnE Life Science. 339-352. doi: 10.18502/kls.v2i6.1056.

Yuksel I dan Dagdeviren M. 2007. Using the analytic network process (ANP) in a SWOT analysis - a case study for a textile firm. Information Science. 177 (2007): 3364-3382. doi: :10.1016/j.ins.2007.01.001 